\title{
A Low Cost and Reliable Dimmable Ballast Topology with Inherent Power Regulation and Insensitivity to Lamp Characteristics
}

\author{
C.P. Liu \\ N.K. Poon \\ M.H. Pong \\ Y.P. Chan \\ D.D.C. Lu \\ Department of Electrical \& Electronic Engineering, \\ Power Electronics Laboratory, The University of Hong Kong, Pokfulam Road, \\ Hong Kong, China \\ Email: cpliu(àeechku.hk, nkpoon@eee.hku.hk, mhp@oee.hku.hk
}

\begin{abstract}
The output power of the proposed dimmable ballast topology is self-regulated and insensitive to the lamp characteristics. Accurate dimming operation with rather constant filament power can be realized simply by open loop control of the switching frequency of the converter. It can provide reliable operation during lamp ignition with fault conditions or even short circuit without the need of current sensing circuits. Prototype was built for experimental verifications. For completeness, a simple ultra low dimming method is also proposed together with the theoretical dimming limit considered.
\end{abstract}

\section{INTRODUCTION}

A common way to realize high frequency electronic ballast for fluorescent lamp is shown in Fig. la. The high frequency $A C$ voltage source can be generated by a half-bridge circuit with a series capacitor and then drives the lamp through a $L C$ network. The lamp exhibits resistive characteristic at high frequency after ignition and a commonly used simplified $L C R$ model is shown in Fig. 1b with the filament resistors $R_{t}, R_{2}, R_{3}$ and $R_{4}$ inserted. The $L C$ network provides several important functions. During lamp ignition, the frequency of the $A C$ voltage source is set to the resonant frequency of the $L C$ network. Because lamp resistance $R_{\text {lump }}$ is very high and can be treated as open circuit before ignition, the $L C$ network exhibits very low impedance to the voltage source and absorbs the energy to build up high voltage across the capacitor to ignite the lamp. To guarantee reliable operation during the ignition period, fast response protection circuit is required to close monitoring the inductor current or the capacitor voltage because if the lamp fails to turn on, the current flowing through the $L C$ network is nearly unlimited and can build up continuously to a dangerous level that will saturate the inductor and bum out the semiconductors that generating the voltage source. Another function of the $L C$ network is to facilitate the dimming operations. One of the most frequently used methods is to control the current delivered to the lamp by control the impedance of the inductor. This can be realized by varying the frequency of the $A C$ voltage source in the range below the resonate frequency of the $L C$ network. The drawback is that the determination of the inductance and actual output power to the lamp depends much on the lamp characteristics. Another dimming control method is to control the phase $\varphi$ between the $A C$ voltage source and the inductor current proposed in [1]. It provides a linear dimming curve between the lamp power and $\varphi$ but a special controller with phase detection is required.

A topology with inherent output power regulated characteristic is proposed for electronic ballast realization. It can provide reliable operation during lamp ignition with fault conditions or even short circuit without the need of current sensing and fast acting protection circuits because of the inherent power limiting features and the lamp power can be adjusted easily and accurately by open control of the switching frequency or the $D C$ link voltage.

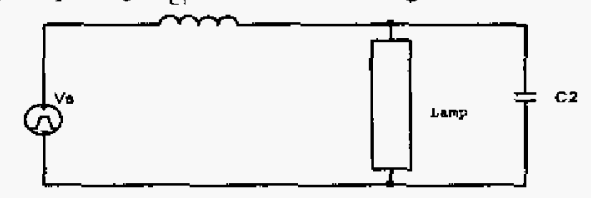

Fig. la Practical electronic ballast configuration



Fig.lb Simplified equivalent circuit model

\section{BASIC OPERATION IDEA}

The basic idea of the topology is proposed in [2][3]. The power regulated feature is based on the charging and discharging characteristics of capacitor with suitable voltage clamping. The basic circuit configuration is shown in Fig. 2. Unlike conventional half-bridge circuit, $C_{3}$ and $C_{4}$ are not intended to operate at constant voltage.

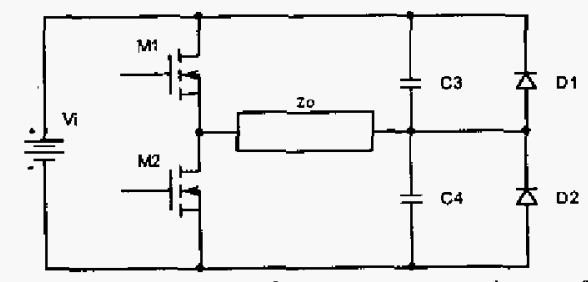

Fig. 2a Circuit diagram with transformer parameters and output filter 




Fig.2b Power transfer when M1 is on

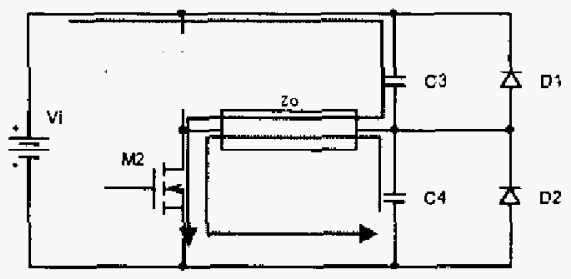

Fig.2c Power transfer when M2 is on

$M_{3}$ and $M_{2}$ are driven on and off alternatively with duty cycle of $50 \%$. Negligible dead time is inserted during the on and of transitions of $M_{1}$ and $M_{2}$ to prevent cross conduction. In Fig. $2 \mathrm{~b}, M_{i}$ is driven on and $M_{2}$ is off, with the assumption that the initial voltage of $C_{3}$ and $C_{4}$ are $V_{i}$ and zero respectively, the energy stored in $C_{3}$ discharges to $Z_{p}$ through $M_{1}$ while $C_{4}$ will be charged up by the input voltage $V_{i}$ through $Z_{\alpha}$. When $C_{4}$ is charged up to $V_{i}$, the voltage across $C_{3}$ is zero and all the stored energy has been released to $Z_{0}$. Further discharging and charging of $C_{3}$ and $C_{4}$ is ceased even when $Z_{o}$ is inductive because of the present of clamping diodes $D_{l}$ and $D_{2}$. At this time, the total energy $E_{c}$ delivered to $Z_{o}$ is equal to $C V_{i}^{2}$ if $\mathrm{C3}=\mathrm{CA}=\mathrm{C}$. If $Z_{o}$ is purely resistive, $E_{c}$ dissipates simultaneously to $Z_{o}$ just after the discharging and charging of $C_{3}$ and $C_{4}$. If $Z_{0}$ is not purely resistive, energy will circulate among $Z_{0} C_{3}, D_{1}$ and $M_{1}$ for a certain time $t_{i}$ until the energy equal to $E_{c}$ dissipates to the resistive part of $Z_{0}$. Similarly, when $M_{2}$ is on and $M_{i}$ is off which is shown in Fig.2c, the same amount of energy $E C$ will dissipate to $Z_{o}$ and completed one period of operations. If the switching frequency is $f_{s}$ the total power $P_{a}$ delivered to $Z_{o}$ is given by equation (1) provided that the on time of $\mathrm{M} 1$ and M2 is greater than $t_{c}$ plus the charging time of $C_{j}$ and $C_{4}$.

$$
P_{o}=2 C V_{i}^{2} f_{s}
$$

Equation (1) shows that the output power is insensitive to $Z_{o}$ and can be controlled by the switching frequency $f_{s}$, the supply voltage $V_{i}$ or the capacitance of $C_{3}$ and $C_{4}$ and the maximum power that can delivery to the $L C$ network during resonate startup is limited.

\section{DETAILED OPERATION AND DESIGN PROCEDURES OF THE PROPOSED DIMMABLE BALLAST}

Dimmable ballast can be realized by replacing $Z_{o}$ with the $L C R$ circuit described in section I. The circuit configuration is shown in Fig. 3a with a transformer $T_{i}$ added to increase the design freedom. The reflected equivalent model is shown in Fig. 3b. A design example is given in this section which uses the proposed topology to drive a T8 TLD36W/54 fluorescent lamp with dimming range from $100 \%$ to $25 \%$ of full lamp power. Only switching frequency control is applied for dimming operation for simplification. From equation (1), the output power is proportional to the switching frequency when the DC link voltage and the capacitance of $C_{3}$ and $C_{4}$ are fixed.



Fig.3a Proposed dimmable ballast configuration



Fig.3b Equivalent reflected circuit proposed in Fig.3a

To avoid the switching frequency from entering the audible range, the switching frequency at full output power is set to be $110 \mathrm{kHz}$. This implies at $25 \%$ dimming operation, the switching frequency is $27.5 \mathrm{kHz}$. With $\mathrm{V}_{i}$ chosen to be $300 \mathrm{VDC}, \mathrm{C}_{3}$ and $\mathrm{C}_{4}$ is then calculated by equation (1). $2 \mathrm{nF}$ is selected for $\mathrm{C}_{3}$ and $\mathrm{C}_{4}$ and the expected output power is $39.6 \mathrm{~W}$ which is a little bit higher than the required power for T8 TLD36W/54 to account for the power loss of the ballast. The resonate frequency of the LC network formed by $L_{1}$ and $C_{2}{ }^{\prime}$ is also set to $110 \mathrm{kHz}$ for resonate lamp ignition. $\mathrm{C}_{2}$ is chosen to provide sufficient heater current and if possible to set at a value such that the LCR network formed by $L_{1}, C_{2}$ and $R_{\text {lamp }}$ at full output power is nearly critically damped during the energy circulating period described in Il to reduce voltage ringing. In this design example, the turn ratio of $T_{1}$ is $1: 1.67$ and $C_{2}$ is chosen to be $2.35 \mathrm{nF}$ formed by two $4.7 \mathrm{nF}$ standard capacitor in series connection. The reflected capacitance $\mathrm{C}_{2}$ ' is $6.55 \mathrm{nF}$ and $\mathrm{L}_{1}$ is then calculated to be $300 \mathrm{uH}$ with resonant frequency $=$ $113.5 \mathrm{kHz}$. Fig. $3 \mathrm{c}$ shows the expected waveforms of the proposed ballast at full output power 




Fig, 3c The expected operating waveforms of the designed ballast prototype at full output power

From $t_{0}$ to $t_{I}$ ( $M_{l}$ is on and $M_{2}$ is off):

During this period, $V_{s}=V_{j}$ and $C_{4}$ is being charged up and $C_{3}$ is discharging. The reflected Lamp voltage $V_{\text {lamp }}^{\prime}$ is given by the equation (2).

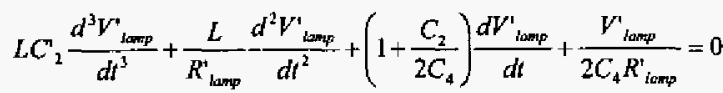

$$
\begin{aligned}
& \text { Where } \quad V_{\text {lamp }}^{\prime}\left(t_{0}\right)=0,\left.\frac{d V^{\prime}{ }_{\text {tamp }}}{d t}\right|_{t=I_{d}}=0,\left.\frac{d^{2} V_{\text {lamp }}^{\prime}}{d t^{2}}\right|_{t=r_{0}}=\frac{V_{1}}{L C_{2}}
\end{aligned}
$$

The inductor current is given by equation (3).

$$
I_{L}(t)=C_{2} \frac{d V^{\prime}}{d t}+\frac{V_{\text {lamp }}^{\prime}}{R_{\text {tamp }}^{\prime}}
$$

and $V_{C 4}$ is given by equation (4)

$$
V_{C 4}(t)=\int_{0}^{1} C_{2} \frac{d V_{\text {tamp }}^{\prime}}{d t}+\frac{V_{\text {lamp }}^{\prime}}{R_{\text {lamp }}^{\prime}} d t
$$

The turns ratio of transformer $T_{1}$ should be chosen such that the reflected capacitance $C_{2}{ }^{\prime}$ and lamp resistance $R^{\prime}$ iamp is large enough and small enough respectively to provide enough $I_{L}$ to charge up $C_{4}$ to $V_{i}$ well within the on period of $M_{l}$.

From $t_{.}$to $t_{2}\left(M_{I}\right.$ is on and $M_{2}$ is off)

$C_{4}$ is charged up to $V_{i}$ and $D$, start to conduct. The energy stored in $L_{1}$ and $C_{2}$ continuously deliver to the Lamp. Since $D_{I}$ and $M_{I}$ are on, the $L C R$ network changes to a parallel connected $L C R$ network when the heater resistances are neglected. The energy delivery time $t_{c}$ depends on the $Q$ factor of the $L C R$ network. For $Q \leq 0.5$, almost all power can deliver to the lamp during the on time of $M_{l}$. During dimming operation, the lamp resistance increases and hence increases the $\mathrm{Q}$ factor. This increases the energy delivery time but fortunately, the switching frequency is reduced during dimming operation, so there is much more time reserved.

From $t_{2}$ to $t_{3}\left(M_{1}\right.$ is on and $M_{2}$ is off)

All energy has been delivered to the lamp.

From $t_{3}$ to $t_{4}\left(M_{1}\right.$ is off and $M_{2}$ is on)
The operation is similar to the period from $t_{0}$ to $t_{l}$ and will not be discussed here.

\section{EXPERIMENTAL RESULTS}

A prototype was built according to the design parameters given in III. The parameters shown in Fig. 3c were measured from the prototype. Fig. 4a, Fig. 4b and Fig. $4 \mathrm{c}$ shows the waveforms at full lamp power, dimmed to $50 \%$ and $25 \%$ respectively. $\mathrm{CHI}=V_{s}, \mathrm{CH} 2=V_{C 4}, \mathrm{CH} 3=$ $V_{\text {lamp }}$ and $\mathrm{CH} 4=I_{L}$. Table 1 shows the measured results of some important parameters. The calculated input power according to equation (1) matches with the results. In addition the filament power tends to increase and compensate the decrease in lamp current which favors the dimming operation.



Fig-4a Maximum output power

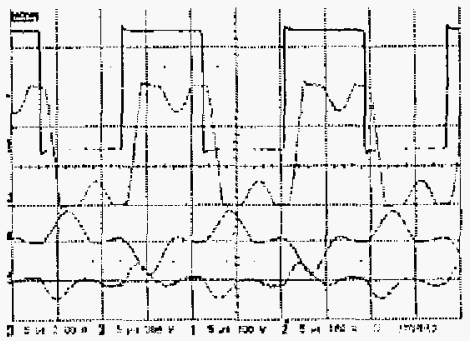

Fig. $4 \mathrm{~b}$ Dimmed to $50 \%$



Fig.4c Dimmed to $25 \%$ 


\section{Practical Consideration}

Commercial dimmable ballasts may require very low dimming levels $(<10 \%)$. Our current demonstration shows that in order to achieve such low levels, the operating frequency or the DC link voltage of the ballast theoretically has to be very low, which causes audible problem and also the instability of the lamp. We therefore proposed a 2-dimensional dimming method which integrates with the topology described in section Il [2] [3] in order to achieve ultra low dimming levels to the theoretical limit of $0 \%$.

The basic idea is to introduce a duty cycle factor $D$, which is superimposed on the operating frequency as seen in Fig. 5. During the ON cycle period, normal switching operation continues. When OFF cycle begins, there is no switching operation, i.e. no power is delivering to the output.

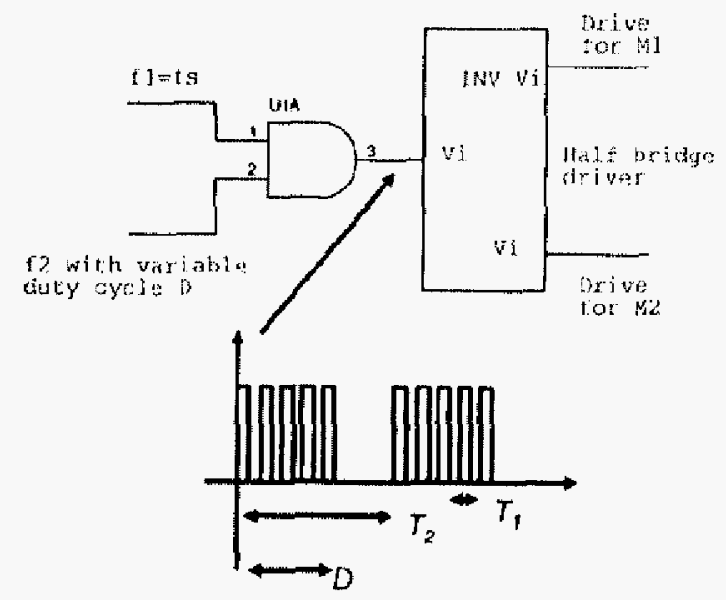

Fig.5 Simplified model with corresponding switching waveform

The output power is simply given by equation (5)

$P_{o}=2 C V_{i}^{2} f_{s} \mathrm{D}$

The duty cycle of the switching circuit gives an extra dimension to control the power. A high enough frequency is selected to avoid the fluorescent lamp turns off unintentionally, i.e. the frequency of the $O N$ period is high enough so that the lamp does not realized for some part of times there are no energy delivered to it.

\section{CONCLUSION}

A topology with inherent output power regulation for implementation of dimming ballast is presented. The output power to the lamp can be controlled easily and accurately by controlling the switching frequency (verified experimentally), the $D C$ link voltage or two capacitor values (verified mathematically) without the need of feedback control. The inherent power limiting features provides more reliable operation during resonant lamp ignition even without current sensing and fast response protection circuit. The calculation of output power to lamp is simple and insensitive to the lamp characteristics. All these features can greatly simplify the design and hence lowering the cost. A ballast prototype was built and some design considerations are stated. Waveforms and important parameters are measured and matched with the calculated results. The measured results also show that the filament power is rather constant during dimming operation which favors the lamp life. Dimming level consideration is discussed with a proposed solution to achieve ultra low dimming levels to the theoretical limit of $0 \%$.

\section{REFERENCE}

[1] Ribarich, T.J.; Ribarich, J.J.: "A new control method for dimmable high-frequency electronic ballasts"Industry Applications Conference, 1998. Thirty-Third IAS Annual Meeting. The 1998 IEEE , Volume: $3,12-15$ Oct. 1998 Pages:2038 - 2043 vol. 3

[2] Poon, N.K.; Pong, B.M.H.; Tse, C.K.; A constant-power battery charger with inherent soft switching and power factor correction Power Electronics, IEEE Transactions on, Volume: 18 , Issue: 6 , Nov. 2003 Pages: 1262 - 1269

[3] M.H.Pong, W.C. Ho, N.K. Poon, "A Soft Switching Converter with Power Limiting Feature" IEE Proceedings - Electric Power Applications, January 1999, Vol.146, No.1, p.95-p.102.

[4] Tetri, E.; Effect of cathode heating on lamp life in dimming use Industry Applications Conference, 2001 Thirty-Sixth IAS Annual Meeting. Conference Record of the 2001 IEEE, Volume: 2, 30 Sept.-4 Oct. 2001 Pages:895 - 900 vol.2

[5] A comparative study on dimming control methods for electronic ballasts Ho, Y.K.E.; Lee, S.T.S.; Chung, H.S.-H.; Hui, S.Y.; Power Electronics, IEEE Transactions on, Volume: 16, Issue: 6, Nov. 2001 Pages: 828 - 836

\begin{tabular}{|l|l|l|l|l|l|l|l|}
\hline $\begin{array}{l}\text { Input Voltage } \\
V_{i}\end{array}$ & $\begin{array}{l}\text { Input } \\
\text { power }\end{array}$ & $\begin{array}{l}\text { Calculated } \\
\text { input power }\end{array}$ & Lamp power & Lamp rms & $\begin{array}{l}\text { Filament } \\
\text { current }\end{array}$ & Filament power & $\begin{array}{l}\text { Total output } \\
\text { power }\end{array}$ \\
\hline $300.0 \mathrm{~V}$ & $39.53 \mathrm{~W}$ & $39.6 \mathrm{~W}$ & $\begin{array}{l}33 \mathrm{~W} \\
(\mathrm{fs}=110 \mathrm{KHz})\end{array}$ & $0.350 \mathrm{Arms}$ & $0.178 \mathrm{Arms}$ & $1.301 \mathrm{~W}$ & $34.302 \mathrm{~W}$ \\
\hline $300.0 \mathrm{~V}$ & $19.60 \mathrm{~W}$ & $19.8 \mathrm{~W}$ & $\begin{array}{l}16 \mathrm{~W} \\
(\mathrm{fs}=55 \mathrm{KHz})\end{array}$ & $0.160 \mathrm{Arms}$ & $0.210 \mathrm{Atms}$ & $0.798 \mathrm{~W}$ & $16.798 \mathrm{~W}$ \\
\hline $300.0 \mathrm{~V}$ & $10.65 \mathrm{~W}$ & $9.9 \mathrm{~W}$ & $\begin{array}{l}7.2 \mathrm{~W} \\
(\mathrm{fs}=27.5 \mathrm{KHz})\end{array}$ & $0.065 \mathrm{Arms}$ & $0.244 \mathrm{Amms}$ & $0.865 \mathrm{~W}$ & $8.065 \mathrm{~W}$ \\
\hline
\end{tabular}

Table 1 Measured experimental results 